\title{
BMJ Open Exploring the therapeutic alliance in Belgian family medicine and its association with doctor-patient characteristics: a cross-sectional
} survey study

\author{
Pauline Boeckxstaens, ${ }^{1}$ Annelou Meskens, ${ }^{1}$ Aline Van der Poorten, ${ }^{1}$ \\ Anne-Catherine Verpoort, ${ }^{1}$ Elizabeth Ann Sturgiss (i) ${ }^{2,3}$
}

To cite: Boeckxstaens $P$, Meskens A, Van der Poorten A, et al. Exploring the therapeutic alliance in Belgian family medicine and its association with doctor-patient characteristics: a cross-sectional survey study. BMJ Open 2020;10:e033710. doi:10.1136/ bmjopen-2019-033710

- Prepublication history and additional material for this paper are available online. To view these files, please visit the journal online (http://dx.doi. org/10.1136/bmjopen-2019033710).

Received 20 August 2019 Revised 15 December 2019 Accepted 31 December 2019

\section{Check for updates}

(C) Author(s) (or their employer(s)) 2020. Re-use permitted under CC BY-NC. No commercial re-use. See rights and permissions. Published by BMJ.

${ }^{1}$ Department of Public Health and Primary Healthcare, Ghent University, Gent, Belgium ${ }^{2}$ Department of General Practice, Monash University, Melbourne, Victoria, Australia

${ }^{3}$ National Centre for Epidemiology and Population Health, The Australian National University, Canberra, Australian Capital Territory, Australia

Correspondence to Dr Elizabeth Ann Sturgiss; liz.sturgiss@monash.edu

\section{ABSTRACT}

Objectives Patient-centred care is related to better health outcomes, greater patient satisfaction and reduced healthcare costs. One of the core components of patientcentred care, defined in the patient-centred clinical method, is enhancing the patient-doctor relationship. In this study, we aim to measure the therapeutic alliance in consultations between patients and family doctors in Belgium, and explore which patient, provider and practice characteristics are associated with the strength of the therapeutic alliance.

Design Cross-sectional cohort study using the Working Alliance Inventory for General Practice (WAI-GP). The patients and family doctors completed a survey after the consultation. The survey consisted of the WAI-GP, demographics, consultation characteristics and variables related to the patient-doctor relationship.

Setting Belgian primary care.

Participants Every third patient (both practice and house call visits) was invited to participate. 170 patient-doctor dyads from four practices were included. Total of 10 doctors (30\% men, age range $24-63$ years) and 170 patients (35.9\% men, age range 18-92 years). Primary and secondary outcome measures Primary outcome was the WAI-GP score and its correlations with characteristics of the doctor (gender, age) and patients (gender, age, chronic disease, number of annual consultations).

Results The median WAI-GP score reported after these consultations was $4.5 \pm 0.62$. Higher WAl-GP scores were reported for consultations with male doctors and by older patients. In the subsample of patients with a chronic illness, higher WAI-GP scores were reported by patients who had more than 10 follow-up consultations per year.

Conclusions Consultation quality is an important aspect of healthcare, but attention is needed to understand how the WAI-GP performs in relation to variables that are beyond control, such as gender of the physician, age of the patient and variables related to building continuity of care. This has implications for the measurement of quality of healthcare.
Strengths and limitations of this study

- This study was informed by the theory of Working Alliance, originally developed and used in psychology.

- The survey was forward and back translated from English to Dutch.

- This is a replication of a study in another international healthcare setting, Australia.

- The data were collected from four practices and this is a small sample of practices.

\section{INTRODUCTION}

Patient-centred care (PCC) is widely accepted as a core value of primary care. ${ }^{1}$ Family doctors often develop long-standing therapeutic relationships with their patients, which they build through many different encounters. ${ }^{2}$ Over the course of these encounters, they become familiar with their patients' personalities and get a more in depth knowledge of their illness narrative. ${ }^{3}$ One of the most established models of PCC is the patient-centred clinical method (PCCM) developed by Stewart and her team. ${ }^{4}$ The PCCM was developed as a clinical model for teaching and training students but it also entails qualitative tools and quantitative measures to study the concept of PCC in the clinical practice. The PCCM proposes four interactive components: exploring the health, disease and illness experience; understanding the whole person; finding common ground and enhancing the patient-doctor relationship. ${ }^{4}$

The Institute of Medicine (IOM) acknowledges PCC as one of the six key objectives to improve healthcare. ${ }^{5}$ As such, the IOM explicitly considers PCC as a domain of quality. ${ }^{5}$ If we want to further explore whether and how PCC can perform as a quality indicator, there is an urgent need to better understand the 
processes of PCC. This is especially important in an era of increasing pay for quality and the introduction of pay for performance systems. ${ }^{6}$ When looking at current indicators of quality of care, for instance, in the UK Quality and Outcomes Framework, ${ }^{7}$ there is an emphasis on disease-specific indicators, which do not always enhance patient-centred approaches in healthcare. For instance, the quality indicators for chronic obstructive pulmonary disease management are mostly based on whether the patient has had a spirometry, has had an oxygen saturation measurement recorded, has had an assessment of breathlessness or has had influenza immunisation, while not a single indicator directly pertains to patient experience or impact of the illness on the patients daily life. ${ }^{7}$

A potential process measure for primary care is the therapeutic alliance, which has been closely studied in the field of psychology. The 'Working Alliance' is a concept that was proposed in 1979, which consists of three main components: the agreement between patient and therapist on treatment goals, the agreement on which tasks or interventions are necessary to reach these goals and the affective bond between patient and therapist. ${ }^{8}$

The Working Alliance has been studied in a variety of healthcare settings, including psychotherapeutic and physiotherapeutic rehabilitation, where a strong alliance was found to be associated with better treatment outcomes, as well as better quality of life..$^{9-11}$ In the original work from psychology, the Working Alliance Inventory (WAI) was completed by both the psychologist and the client. However, there was low correlation between family doctor and patient scores when used in primary care ${ }^{12}$ and this mirrors discordant findings in other measures used in primary care. ${ }^{1314}$ For this reason, we are most interested in the patient's perception of the therapeutic alliance and have proceeded with that measure alone.

A commonly used instrument to measure the therapeutic alliance is the WAI. Originally, this questionnaire consisted of 36 items, but was revised to the 12-item WAI Short Form Revised. ${ }^{15} 16$ The questionnaire covers the three areas defined in the original Working Alliance framework: goal, task and bond. ${ }^{8}$ An adaptation of the WAI specifically for use in primary care, WAI for General Practice (WAI-GP), was developed in Australian primary care and its psychometric properties were found to be valid in that setting. ${ }^{1718}$

The link between a strong therapeutic alliance and improved patient health outcomes in psychology holds great promise for primary care. The WAI-GP has already been found to have concurrent validity for measures of shared decision making, depth of relationship, patient centredness and empathy. ${ }^{1718}$

This exploration is important if the WAI-GP is to be used in primary care research to determine if the patient measure of the WAI-GP is responsive to changes in the primary care context as well as applicable in an international healthcare setting. Most research on the doctorpatient relationship in healthcare focuses on solely the 'bond' section of the alliance (warmth and respect).
Looking at measures beyond the doctor-patient 'bond' as we see increasing interprofessional collaboration and task shifting in primary care. This is especially true for patients with chronic conditions when "goal' setting and decision on 'tasks' may be important for primary care effectiveness.

In this study, we aim to measure the therapeutic alliance in consultations between patients and family doctors in Belgium, and explore which provider characteristics (age, sex, years in practice), patient characteristics (age, sex morbidity), contact characteristics (consultation or house call, number of contacts per year, reason for encounter) and relationship characteristics (duration of the therapeutic relationship, patient preference) are associated with the strength of the therapeutic alliance according to the patient's measure.

\section{METHOD}

We conducted a cross-sectional survey study assessing the correlation between WAI-GP-scores and patient, physician and consultation characteristics in consultations between a patient and their family doctor in Belgium.

The WAI-GP has been validated for primary care in Australian GP where it was found to have concurrent validity with measures of shared decision making, depth of relationship, patient centredness and empathy. ${ }^{17} 18$ First, the WAI-GP was translated by means of backwardforward procedure by two independent interpreters to get the final version of the Dutch WAI-GP (online supplementary appendix A). The WAI-GP consists of a doctor and patient questionnaire, and has 10 and 12 questions, respectively. Each question is scored on a 5-point Likertscale, varying from 'rarely or never' (1) to 'always' (5). In this study, it was decided to use the total WAI-GP score, and not the subscores of the task, goal and bond areas.

We added a second survey to the WAI-GP to collect provider characteristics (age, sex, working experience), patient characteristics (age, sex, morbidity), contact characteristics (type of contact, reason for encounter, annual number of contacts) and variables relating to the patientdoctor relationship (duration of the therapeutic relationship, whether the patient has a preference for a certain doctor and whether they got to consult their preferred doctor) (online supplementary appendix A).

The Dutch WAI-GP survey was administered in four GPs with the goal of including a minimum of 150 patientdoctor dyads. A statistical consultant suggested that 150 dyads would be enough to detect the differences we were interested in. The included practices consisted of two solo practices; one duo practice with two family doctors and two residents and a group practice with four family doctors. Consultations in patients under the age of 18 and patients who were unable to provide informed consent were excluded.

The patients were informed of the study by a poster displayed in the waiting room, starting from May 2018. From July to September 2018, a family doctor trainee 
was present in the practice 1 day a week and invited every third consulting patient (in practice visits and house calls) to participate. Before being given the questionnaire, the patients received the study information both verbally and in writing via the informed consent form, and a researcher was available for further questions while they filled out the survey.

The survey data was deidentified, coded and processed in SPSS. The associations between population characteristics and the WAI-GP score were assessed using Spearman correlation (for correlation of the WAI-GP with patient and GP age) and Mann-Whitney U or Kruskal-Wallis tests (for correlation with the remaining categorical variables). A $p<0.05$ was considered statistically significant.

\section{Patient and public involvement statement}

Patients were not involved in the planning or conduct of this specific research project.

\section{RESULTS}

Data were collected for 170 contacts (table 1). Two consultations were excluded because of missing data. Ten family doctors participated aged between 24 and 63 years, $30 \%$ were male, $70 \%$ had more than 10 years of working experience. The number of included consultations per family doctor ranged from 14 to 30 consultations, with the exception of one of the physicians with three included consultations.

A total of 170 patients participated in the study. The mean age was 54.4 years, ranging from 18 to 92 years. Almost two-thirds (64.1\%) of the included patients were female.

$81.2 \%$ of the contacts happened in the practice, with the main reasons for encounter being treatment and diagnosis. About half the patients $(47.6 \%)$ visit with their doctor less than five times a year, while $22.9 \%$ is seeing their physician more than 10 times a year on average.

Nearly $40 \%$ had been consulting with their current doctor for over 10 years. Seventy per cent of the patients responded that they had a preference for a certain doctor in their practice and almost $90 \%$ of these patients with a preference saw their preferred physician in the study consultation.

The median WAI-GP score was $4.5 \pm 0.62$, with $7.6 \%$ of the patients giving the maximum score of 5 on all questions.

The age of the doctor was not significantly correlated with the WAI-GP (table 2). However, the sex of the family doctor was significantly correlated with the patient WAI-GP score $(\mathrm{p}=0.008)$ - male physicians generally received higher scores than their female colleagues. No significant correlation was found for the number of years of experience of the doctor.

The patient's age significantly correlates with the patient WAI-GP score $(\mathrm{p}=0.000)$, older patients give higher scores than younger patients. The patient's sex was not significantly correlated with the WAI-GP.
Table 1 Participant characteristics for cross-sectional survey in Belgian family medicine clinics

\begin{tabular}{|c|c|c|c|}
\hline \multicolumn{4}{|c|}{ Participant characteristics } \\
\hline \multirow{7}{*}{$\begin{array}{l}\text { Family doctor } \\
(n=10)\end{array}$} & Age (years) & Mean (range) & $45.2(24-63)$ \\
\hline & Sex & Male & $3(30 \%)$ \\
\hline & & Female & 7 (70\%) \\
\hline & Experience & $>10$ years & $7(70 \%)$ \\
\hline & & $5-10$ years & $1(10 \%)$ \\
\hline & & $1-5$ years & $1(10 \%)$ \\
\hline & & $<1$ year & $1(10 \%)$ \\
\hline \multirow[t]{3}{*}{ Patient $(n=170)$} & Age (years) & Mean (range) & $54.4(18-92)$ \\
\hline & Sex & Male & $61(35.9 \%)$ \\
\hline & & Female & $109(64.1 \%)$ \\
\hline \multirow[t]{13}{*}{ Contact $(n=170)$} & $\begin{array}{l}\text { Type of } \\
\text { contact }\end{array}$ & In-practice & $138(81.2 \%)$ \\
\hline & & House-calls & $32(18.8 \%)$ \\
\hline & $\begin{array}{l}\text { Annual no of } \\
\text { contacts }\end{array}$ & $<5 /$ year & $81(47.6 \%)$ \\
\hline & & 5-10/year & $50(29.4 \%)$ \\
\hline & & $>10 /$ year & $39(22.9 \%)$ \\
\hline & $\begin{array}{l}\text { Reason for } \\
\text { encounter }\end{array}$ & Diagnosis & $49(28.8 \%)$ \\
\hline & & Reassurance & $3(0.02 \%)$ \\
\hline & & $\begin{array}{l}\text { Discussion of } \\
\text { results }\end{array}$ & $16(0.09 \%)$ \\
\hline & & Treatment & $53(31.2 \%)$ \\
\hline & & $\begin{array}{l}\text { Routine check- } \\
\text { up }\end{array}$ & $19(11.2 \%)$ \\
\hline & & Follow-up & $21(12.3 \%)$ \\
\hline & & Referral & $7(4.1 \%)$ \\
\hline & & Rather not say & $2(1.2 \%)$ \\
\hline \multirow[t]{8}{*}{$\begin{array}{l}\text { Relationship } \\
(n=170)\end{array}$} & $\begin{array}{l}\text { Duration } \\
\text { therapeutic } \\
\text { relationship }\end{array}$ & $>10$ years & $65(38.2 \%)$ \\
\hline & & $5-10$ years & $29(17.1 \%)$ \\
\hline & & $1-5$ years & $55(32.4 \%)$ \\
\hline & & $<1$ year & $21(12.4 \%)$ \\
\hline & $\begin{array}{l}\text { Patient has } \\
\text { preferred } \\
\text { doctor }\end{array}$ & Yes & 119 (70\%) \\
\hline & & No & $51(30 \%)$ \\
\hline & $\begin{array}{l}\text { Visit } \\
\text { was with } \\
\text { preferred } \\
\text { doctor? }\end{array}$ & Yes & 107 (89.9\%) \\
\hline & $(n=119)$ & No & $12(10.1 \%)$ \\
\hline \multirow[t]{3}{*}{ Scores $(n=170)$} & $\begin{array}{l}\text { WAI-GP } \\
\text { patient }\end{array}$ & Mean (range) & $4.3(2.3-5.0)$ \\
\hline & & Median $( \pm S D)$ & $4.5 \pm 0.62$ \\
\hline & & $\begin{array}{l}\text { Maximum score } \\
\text { (5) }\end{array}$ & 13 (7.6\%) \\
\hline
\end{tabular}

WAI-GP, Working Alliance Inventory for General Practice. 
Table 2 Correlation between WAI-GP score measuring therapeutic alliance and doctor-patient characteristics

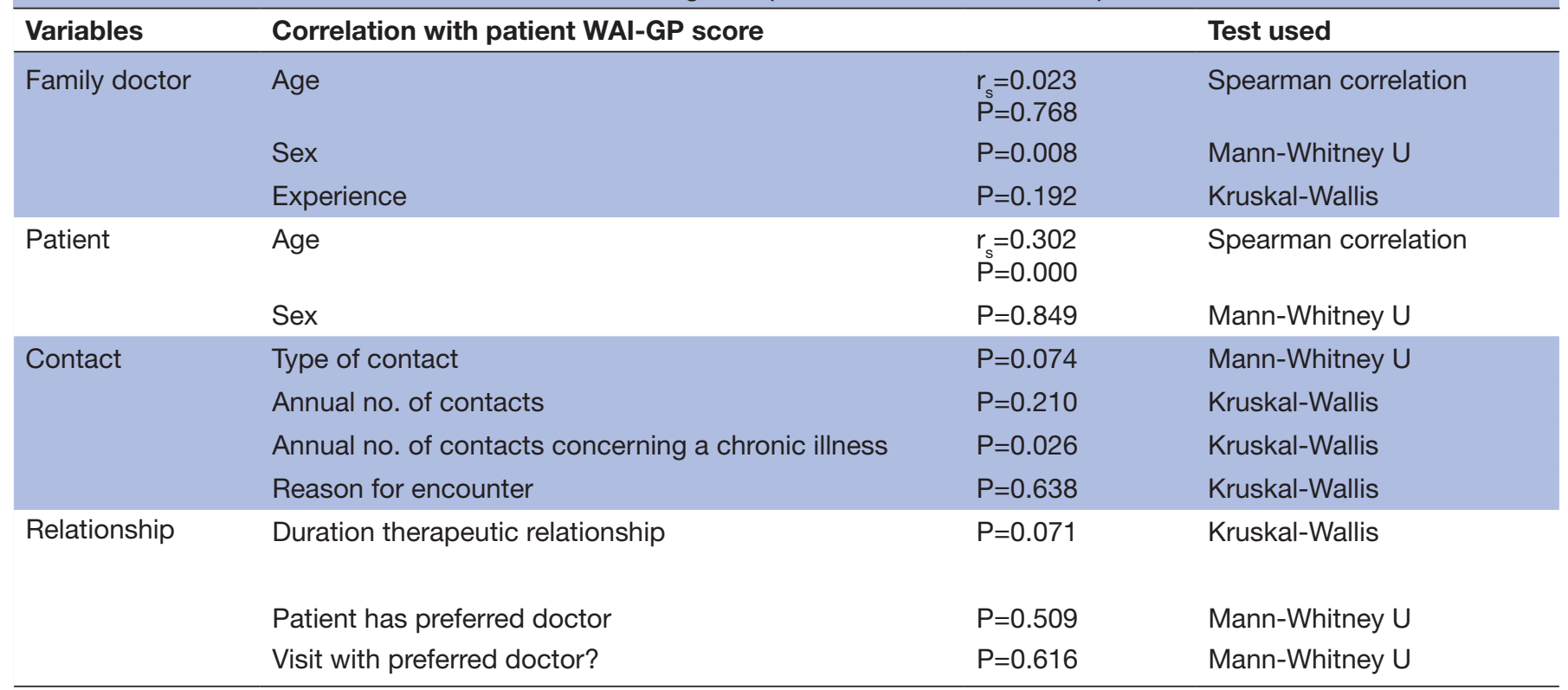

WAI-GP, Working Alliance Inventory for General Practice.

The type of contact (house-call vs in-practice consultation) was not correlated with a difference in WAI-GP scores, nor was the annual number of contacts or the reason for encounter. However, when looking at the number of contacts concerning a chronic illness, patients who consulted their doctor more than ten times a year did score significantly higher than patients who consulted less often, or patients without chronic illness. There was no significant correlation found for the duration of the therapeutic relationship, or patient preference for the doctor that they saw.

\section{DISCUSSION}

The median WAI-GP score was $4.5 \pm 0.62$, male physicians received higher WAI-GP scores than their female colleagues and older patients tended to give higher scores than younger patients. When looking at the total number of contacts per year, no significant correlations could be found, however, when looking at the number of contacts concerning a chronic illness, we did find that a higher number of contacts was correlated with a higher WAI-GP score. This seems to indicate that a closer contact between patient and provider contributes to a stronger therapeutic alliance.

When we compare this to the mean scores found for the WAI-Rehabilitation Dutch version (WAI-ReD) in physical rehabilitation $(4.2 \pm 0.7),{ }^{19}$ the WAI in psychiatric rehabilitation $(5.64 \pm 0.75$ this study used a 7-point Likert scale, readjusted for a 5-point scale this would compare to a $4.02 \pm 0.53$ mean $)^{20}$ or the physician-patient working alliance in rheumatology $(70.74 \pm 11.73$ - this study used the total score and a 7-point Likert scale, readjusted for a 5-point scale this would compare to a mean of $4.21 \pm 0.69),{ }^{21}$ we can conclude that the strength of the therapeutic alliance in family medicine is comparable to that in other healthcare fields. The study on the WAI-ReD found a $8.7 \%$ ceiling effect, ${ }^{19}$ which is comparable to the $7.6 \%$ that was found in this study, and indicates that the WAI as a measure has a low occurrence of response bias.

Our finding that male physicians scored more highly mirrors other research in patient ratings of their physician's care. ${ }^{22}$ A study in gynaecology showed that female gynaecologists were $47 \%$ less likely to receive top patient satisfaction scores compared with their male counterparts, ${ }^{23}$ and male physicians were credited with being more patient-centred than female physicians, even though female physicians tend to be more patient centred overall. ${ }^{24}$ These results indicate a certain bias with regard to female physicians that should be taken into account when using therapeutic alliance or patient satisfaction as a measure for quality of care. This has implications as more health systems use various patient satisfaction or other patient reported outcomes in the measurement of quality in healthcare. We suggest that future use of this and other patient-reported outcomes specifically look at correlation with the gender of the physician to detect bias.

A study in an outpatient spine clinic found that younger patients gave lower patient satisfaction scores, ${ }^{25}$ and a UK patient experience survey also showed that the likelihood of positive responses increased with age. ${ }^{26}$ These findings are in line with our own study results, and indicate that we should be careful when comparing patient scores for different age groups and as a marker for quality healthcare.

The number of contacts is representative of provider continuity and continuity of care. Multiple studies have shown that a higher continuity in family medicine is associated with better outcomes-through improved preventive 
healthcare ${ }^{27}$ and more adequate cancer screening ${ }^{28}$ - and lower total healthcare costs. ${ }^{29}{ }^{30}$ Our own study has found that patients who see their doctor more frequently had a higher measure of therapeutic alliance, but there was no correlation with the length of time the patient had known their doctor. These results seem to suggest that provider continuity needs to be promoted further to improve the quality of primary care.

Although 170 patients is a reasonably sized group, 10 doctors and 4 practices is a rather small study sample, so any results from this study should be interpreted with that in mind. During the study, some questions of the WAI-GP were misinterpreted or difficult to understand for some patients. We would like to perform cognitive interviewing with patients both in Belgium and Australia to explore the deeper understanding of the questions. Moreover, not all relevant variables could be included in the questionnaire due to the risk of it becoming too extensive, so it is possible that there are relevant demographic or consultation characteristics that we were not able to explore.

The result of finding higher WAI-GP scores for patients with chronic conditions who see their GP more than 10 times a year could be further explored with an in-depth qualitative inquiries of these consultations with a high therapeutic alliance. Identifying and describing the necessary skills could help us to train family physicians in the right techniques to facilitate or enhance their therapeutic alliance with patients. It would also be relevant to explore the effect of therapeutic alliance as measured by the WAI-GP on long-term health outcomes.

Additionally, it could be useful to include physicians, and other healthcare providers in the primary care settingsuch as nurses, physiotherapist, dietitians-to examine whether there is a difference in the determinants of the therapeutic alliance, and whether the same techniques might be used to improve their patient-provider relationships. Lastly, if we wish to explore whether the WAI-GP could be used as a quality indicator for processes of PCC, further research will be necessary to better understand how the measure performs in relation to variables that are beyond control such as the sex of the physician and age of the patient.

PCC is related to better health outcomes, greater patient satisfaction and reduced healthcare costs. If we want to think about incentives for PCC performance, we need to study the processes of patient-centred care, their determining factors and how to enhance them. Family medicine provides an interesting context to explore and study these processes of PCC, and more specifically, the development of the therapeutic relationship. This study showed that a higher number of contacts in patients with a chronic illness was related to a stronger therapeutic alliance, more specifically patients who had to consult their GP more than 10 times a year tended to score significantly higher than patients who consulted less. Additionally, we found that female doctors tended to receive lower scores, and younger patients tended to give lower scores.
The WAI-GP is a promising measure as a quality indicator for processes of PCC. In future research, we suggest that attention is given to assess how unmodifiable variables (eg, sex of the physician, age of the patient) relate to the patient measure of WAI-GP, as well as variables related to building continuity of care.

\section{Twitter Elizabeth Ann Sturgiss @LizSturgiss}

Contributors PB and EAS conceived of the study design. AM, AVdP and A-CV collected the data. PB, AM, AVdP and A-CV analysed the data. AM wrote the first draft of the manuscript. PB and EAS revised the manuscript. All authors approved of the final version of the manuscript.

Funding The authors have not declared a specific grant for this research from any funding agency in the public, commercial or not-for-profit sectors.

Competing interests None declared.

Patient consent for publication Not required.

Provenance and peer review Not commissioned; externally peer reviewed.

Data availability statement Data are available on reasonable request. The data are available by request from the authors after appropriate ethics approval.

Open access This is an open access article distributed in accordance with the Creative Commons Attribution Non Commercial (CC BY-NC 4.0) license, which permits others to distribute, remix, adapt, build upon this work non-commercially, and license their derivative works on different terms, provided the original work is properly cited, appropriate credit is given, any changes made indicated, and the use is non-commercial. See: http://creativecommons.org/licenses/by-nc/4.0/.

\section{ORCID iD}

Elizabeth Ann Sturgiss http://orcid.org/0000-0003-4428-4060

\section{REFERENCES}

1 Hudon C, Fortin M, Haggerty JL, et al. Measuring patients' perceptions of patient-centered care: a systematic review of tools for family medicine. Ann Fam Med 2011;9:155-64.

2 Stewart M. Towards a global definition of patient centred care. BMJ 2001;322:444-5.

3 Egnew TR. Suffering, meaning, and healing: challenges of contemporary medicine. Ann Fam Med 2009;7:170-5.

4 Levenstein JH, McCracken EC, McWhinney IANR, et al. The patientcentred clinical method. 1. A model for the doctor-patient interaction in family medicine. Fam Pract 1986;3:24-30.

5 Institute of Medicine (US) Committee on Quality of Health Care in America. Crossing the quality chasm: a new health system for the 21 st century. 2001 2, improving the 21st-century health care system. Washington (DC): National Academies Press (US), 2001.

6 Lester H, Matharu T, Mohammed MA, et al. Implementation of pay for performance in primary care: a qualitative study 8 years after introduction. Br J Gen Pract 2013;63:e408-15.

7 Excellence $\mathrm{NlfHaC}$. Nice quality and outcomes framework indicator UK, 2019. Available: https://www.nice.org.uk/Standards-andIndicators/QOFIndicators [Accessed 23 Jun 2019].

8 Bordin ES. The generalizability of the psychoanalytic concept of the working alliance. Psychotherapy: Theory, Research \& Practice 1979;16:252-60.

9 Elvins R, Green J. The conceptualization and measurement of therapeutic alliance: an empirical review. Clin Psychol Rev 2008;28:1167-87.

10 Ferreira PH, Ferreira ML, Maher CG, et al. The therapeutic alliance between clinicians and patients predicts outcome in chronic low back pain. Phys Ther 2013;93:470-8.

11 Sanches SA, van Busschbach JT, Michon HWC, et al. The role of working alliance in attainment of personal goals and improvement in quality of life during psychiatric rehabilitation. Psychiatric Services 2018;69:903-9.

12 Sturgiss EA, Sargent GM, Haesler E, et al. Therapeutic alliance and obesity management in primary care - a cross-sectional pilot using the Working Alliance Inventory. Clin Obes 2016;6:376-9.

13 Hermans L, Olde Hartman T, Dielissen PW. Differences between GP perception of delivered empathy and patient-perceived empathy: a cross-sectional study in primary care. $\mathrm{Br} J$ Gen Pract 2018;68:e621-6. 
14 Burt J, Abel G, Elliott MN, et al. The evaluation of physicians' communication skills from multiple perspectives. Ann Fam Med 2018;16:330-7.

15 Horvath A. Working alliance inventory Burnaby, Canada, 1992. Available: http://wai.profhorvath.com/ [Accessed 18 Oct 2018].

16 Horvath AO, Greenberg LS. The working alliance: theory, research and practice. Wiley, 1994.

17 Sturgiss EA, Rieger E, Haesler E, et al. Adaption and validation of the working alliance inventory for general practice: qualitative review and cross-sectional surveys. Family practice 2018.

18 Hunik L, Sturgiss E, Galvin SL. Using the working alliance inventory in Australian general practice: a cross-sectional study. 47th NACPRG annual meeting. Toronto, 2019.

19 Paap D, Schrier E, Dijkstra PU. Development and validation of the working alliance inventory Dutch version for use in rehabilitation setting. Physiotherapy Theory and Practice 2018:1-12.

20 Moran G, Mashiach-Eizenberg M, Roe D, et al. Investigating the anatomy of the helping relationship in the context of psychiatric rehabilitation: The relation between working alliance, providers' recovery competencies and personal recovery. Psychiatry Res 2014;220:592-7.

21 Fuertes JN, Anand P, Haggerty G, et al. The physician-patient working alliance and patient psychological attachment, adherence, outcome expectations, and satisfaction in a sample of rheumatology patients. Behav Med 2015;41:60-8.

22 Duberstein P, Meldrum S, Fiscella K, et al. Influences on patients' ratings of physicians: Physicians demographics and personality. Patient Educ Couns 2007;65:270-4.
23 Rogo-Gupta LJ, Haunschild C, Altamirano J, et al. Physician gender is associated with press Ganey patient satisfaction scores in outpatient gynecology. Women's Health Issues 2018;28:281-5.

24 Hall JA, Gulbrandsen P, Dahl FA. Physician gender, physician patient-centered behavior, and patient satisfaction: a study in three practice settings within a hospital. Patient Educ Couns 2014;95:313-8.

25 Bible JE, Kay HF, Shau DN, et al. What patient characteristics could potentially affect patient satisfaction scores during spine clinic? Spine 2015;40:1039-44.

26 Sizmur S, Graham C, Walsh J. Influence of patients' age and sex and the mode of administration on results from the NHS Friends and Family Test of patient experience. J Health Serv Res Policy 2015;20:5-10.

27 Matulis JC, Schilling JJ, North F. Primary care provider continuity is associated with improved preventive service ordering during brief visits for acute symptoms. Health Serv Res Manag Epidemiol 2019;6:233339281982626.

28 Arnold LD, McGilvray MMO, Kyle Cooper J, et al. Inadequate cancer screening: lack of provider continuity is a greater obstacle than medical Mistrust. J Health Care Poor Underserved 2017;28:362-77.

29 De Maeseneer JM, De Prins L, Gosset C, et al. Provider continuity in family medicine: does it make a difference for total health care costs? Ann Fam Med 2003;1:144-8.

30 Bazemore A, Petterson S, Peterson LE, et al. Higher primary care physician continuity is associated with lower costs and hospitalizations. Ann Fam Med 2018;16:492-7. 